University of Nebraska - Lincoln

DigitalCommons@University of Nebraska - Lincoln

\title{
Modeling Genomes to Phenomes to Populations in a Changing Climate: The Need for Collaborative Networks
}

Nika Galic

Syngenta Crop Protection LLC., nika.galic@syngenta.com

\author{
Allyson G. Hindle \\ University of Nevada, Las Vegas \\ John P. DeLong \\ University of Nebraska - Lincoln, jpdelong@unl.edu \\ Karen Watanabe \\ Arizona State University \\ Valery Forbes \\ University of Minnesota
}

See next page for additional authors

Follow this and additional works at: https://digitalcommons.unl.edu/bioscifacpub

Part of the Biology Commons, Finance and Financial Management Commons, Other Ecology and Evolutionary Biology Commons, and the Public Economics Commons

Galic, Nika; Hindle, Allyson G.; DeLong, John P.; Watanabe, Karen; Forbes, Valery; and Buck, C. Loren, "Modeling Genomes to Phenomes to Populations in a Changing Climate: The Need for Collaborative Networks" (2019). Faculty Publications in the Biological Sciences. 827.

https://digitalcommons.unl.edu/bioscifacpub/827

This Article is brought to you for free and open access by the Papers in the Biological Sciences at DigitalCommons@University of Nebraska - Lincoln. It has been accepted for inclusion in Faculty Publications in the Biological Sciences by an authorized administrator of DigitalCommons@University of Nebraska - Lincoln. 


\section{Authors}

Nika Galic, Allyson G. Hindle, John P. DeLong, Karen Watanabe, Valery Forbes, and C. Loren Buck 


\title{
Modeling Genomes to Phenomes to Populations in a Changing Climate: The Need for Collaborative Networks
}

\author{
Nika Galic, Allyson G. Hindle, John P. DeLong, Karen Watanabe, Valery Forbes, and C. Loren Buck
}

Galic: Syngenta Crop Protection LLC, Greensboro, North Carolina, USA, nika.galic@syngenta.com

Hindle: University of Nevada-Las Vegas, Las Vegas, Nevada, USA

DeLong: University of Nebraska-Lincoln, Lincoln, Nebraska, USA

Watanabe: Arizona State University, Phoenix, Arizona, USA

Forbes: University of Minnesota, Saint Paul, Minnesota, USA

Buck: Northern Arizona University, Flagstaff, Arizona, USA

\section{Condensed Abstract}

Climate is changing globally and its impacts can arise at different levels of biological organization; yet, cross-level consequences of climate change are still poorly understood. Designing effective environmental management and adaptation plans requires implementation of mechanistic models that span the biological hierarchy. Because biological systems are inherently complex and dynamic in nature, dealing with complexities efficiently necessitates simplification of systems or approximation of relevant processes, but there is little consensus on mathematical approaches to scale from genes to populations. Here we present an effort that aims to bring together groups that often do not interact, but that are essential to illuminating the complexities of life: empirical scientists and mathematical modelers, spanning levels of biological organization from genomes to organisms to populations. Through interplay between theory, models, and data, we aim to facilitate the generation of a new synthesis and a conceptual framework for biology across levels.

\section{Predicting impacts of climate change from genomes to phenomes to populations}

Climate is changing at a global scale with extreme weather events (Rahmstorf and Coumou 2011), shifts in seasonality and precipitation patterns, and an overall increase in the mean and variance of temperatures as some of the more noticeable consequences (Houghton et al. 2001). These environmental changes can compromise organismal fitness through changes in species phenologies and mismatches with their resources (Parmesan and Yohe 2003), as well as potential intraspecific mismatches during reproductive periods (Williams et al. 2017). Furthermore, extreme weather patterns can increase stress levels which can lead to decreased disease resistance and reduced fitness (Wingfield et al. 2011), potentially jeopardizing population viability and long-term persistence of many species.

Impacts of climate change can arise at different levels of biological organization, either simultaneously or sequentially (Woodward et al. 2010), with different ramifications and feedbacks across levels. Most available information, or that which is being gathered, is specific to levels spanning genomes to individuals over relatively short time-frames; yet, we are interested in how populations respond to altered conditions, if and how they adapt, and how adaptation influences persistence across long time scales. We are even less aware of the potential cascading feedbacks from populations to individuals and genomes and how these connections, either direct or indirect, can buffer or accelerate adverse impacts of a changing environment on species or populations. There is a need to have a mechanistic understanding of nested and non-nested hierarchies (Allen and Starr 2017), i.e. of the bidirectional connections from genotypes to populations in sufficient detail so that relevant feedbacks are captured (Evans et al. 2013). Understanding connectivities and feedbacks is crucial to the design of effective management plans to mitigate the impacts of climate change on populations.

\section{Dealing with complexities across levels of biological or- ganization}

Biological systems are inherently complex and dynamic in nature. Developing models to represent these systems has traditionally focused on defined levels, driven by specific needs and questions. For example, human health applications have been the main driver of novel developments in whole cell modeling. The model of a Mycoplasma genitalium cell realistically accounts for different cellular processes, including DNA decay and repair, gene transcription and translation, metabolism, decay and recycling of RNA, and formation of the dividing rings (Karr et al. 2012). Even though this model is represented as a unit, it is comprised of 28 separate modules that use different mathematical approaches that are linked to represent the whole cell. By extension, scaling up from cells to populations might require numerous additional modules, making the mathematical connection between genes and populations incredibly complex.

Mathematically, complex models can be formulated to include multiple scales of biological processes and organization in the context of multiscale modeling. For example, in pharmaceutical research and chemical risk assessment, physiologically based pharmaco-toxicokinetic (PBPK) models are used to predict the absorption, distribution, metabolism and elimination of chemicals (e.g. drugs and environmental toxicants) in humans and wildlife. In short, PBPK models predict organ and tissue concentrations based on a given chemical exposure (Gibaldi and Perrier 1982). Multiscale models that utilize a PBPK framework as a means of integrating processes across scales include: liver metabolism of acetaminophen in humans to predict variability of effects among different groups of individuals (Sluka et al. 2016); models of the hypothalamic-pituitary-gonadal axis to predict the effect of endocrine active chemicals on fish reproductive end points (Murphy et al. 2005, Li et al. 2011, Gillies et al. 2016), and recent efforts to link across scales for endocrine-active chemicals on 
rainbow trout reproduction leading to population-level effects (Forbes et al. 2019). In addition to a longer history of modeling animal nutrition (Baldwin and Sainz 1995), efforts are being made to model physiology, such as what is being done in the fields of stress physiology (Romero et al. 2015, Del Giudice et al. 2018) and metabolic organization (Jusup et al. 2017). Critical to the success of these efforts is the availability of data to parameterize the models. In order to maintain biologically plausible values, the availability of data will ultimately limit the complexity and predictive power of the models.

Although population-level processes clearly emerge from individual-level processes that themselves depend on physiology, cells, and gene expression, ecological research on populations and species interactions such as competition, predation, and mutualism, has traditionally ignored lower levels of organization. Furthermore, most models of ecological dynamics regard populations as homogeneous compartments expressed as states in differential equations that allow for analytical solutions of equilibria and mathematical tractability. With the realization that population composition and structure influences population dynamics, more structured models started emerging (Caswell 2001, Hastings et al. 2018). These included models representing population structure in several designated groups (e.g. age-or stage-based matrix models) and models representing each individual in the population (e.g. individual-based models) (Grimm and Railsback 2005). Increases in computational power and more flexible modeling approaches are now opening doors to permit representation of hierarchies by including various processes and mechanisms at the levels of cells and tissues.

Still, to further our understanding and mitigation of impacts of a changing environment, we need to find ways of dealing with complexities efficiently, by simplifying systems or approximating relevant processes (Evans et al. 2013). When considering the processes that will be included in a model's mathematical formulation, having clarity on the model's purpose is essential. That is, characteristic spatial and temporal scales may need to be considered in order to simplify equations and "prune" processes that are not essential contributors to model output/prediction(s). One example of a coherent scientific framework, based on a set of mechanistic models describing energy acquisition and allocation, is the Dynamic Energy Budget (DEB) theory (Kooijman 2010, Jusup et al. 2017). Originally developed to better quantify impacts of chemicals on species physiology and life history, DEB models are applied to understand and predict biological responses to various environmental factors (Galic and Forbes 2017), including temperature and resource availability (Kearney and Porter 2009, Jusup et al. 2017). As the currencies in DEB theory are mass and energy, this framework provides a natural link between suborganismal, organismal, population, and ecosystem processes and has often been applied for understanding how impacts of stressors on individual organisms translate into impacts at higher levels (Nisbet et al. 2000, Martin et al. 2013, Galic et al. 2017).

However, there is little consensus on mathematical approaches to scale from genes to populations. Key unanswered questions include: Do all levels of organization need to be modeled explicitly, or can some levels be condensed for simplicity and tractability? If they are all included, does each level need to be addressed with the same degree of detail? Do we need to consider all of the genes and the genome architecture, or can we focus on a subset? Are there any modules that can be treated as universal, such that cross-species variation or evolution can be ignored?
3. The role of microevolution and plasticity in shaping genomes and phenomes

Fundamental to understanding organismal responses to environmental change through time is to understand the roles of evolution and phenotypic plasticity in altering organism performance in response to stressors. While phenotypic plasticity is an individual characteristic, microevolution refers to genotypic changes at the population level. Interactions between environmental change and genotypes distributed within a population can occur both upstream and downstream of phenotypic changes that can be measured as physiological or biochemical specializations of individuals (Diamond and Martin 2016). The linkage between genotype and phenotype within the context of environmental perturbation can be experimentally tracked via reaction norms. A reaction norm encompasses a typical response (or plastic range of responses) to environmental variation by a single genotype (Houston and McNamara 1992, Gotthard and Nylin 1995). Reaction norms are particularly useful in comparisons of closely related populations and may be a key feature of modeling the range of available responses for (sub)populations and ultimately their fate in the face of changing environments.

De facto, each parameter used in models addressing processes from genes to populations reflects an organism's phenotype and thus is subject to evolution and also may have plastic characteristics (DeLong et al. 2016). Predicting changes in these parameters is thus critical to using multi-scale models to capture responses to climate change. Evolutionary approaches such as quantitative genetics link mean trait change to population dynamics but treat genes and their expression across levels of organization as a black box (Lande 1976, Abrams et al. 1993). Alternatively, population genetics focuses on the change in allele frequencies at specific sets of genes, but treats the emergence of phenotypes from genotypes as black boxes (Messer et al. 2016). More recent approaches such as Gillespie Eco-evolutionary Models (GEMs) integrate demographic stochasticity and genetic drift with quantitative genetics in a community context (DeLong and Gibert 2016), but still do not account for all of the steps leading from genes to populations. Although data remain scarce (for mammals, in particular), it is now possible to tease apart the driving forces of phenotypic plasticity versus microevolutionary changes on responses to environmental variability (Boutin and Lane 2014). It is critical to recognize that scaling up from genes to populations likely requires taking into account changes in genes through time.

\section{Collaborative developments across communities of ex- perts}

Tackling any big challenge, especially that of expected and unexpected future changes in climate patterns and consequences for local biota, will require connecting experts across disciplines. The scientific community tends to operate in silos of expertise; for instance, in biological research it is still rare for teams of researchers to span more than two levels of biological organization. It is even more uncommon to include mathematical or theoretical biologists into such efforts from the beginning (but see e.g. Forbes et al. 2017). It is evident that collective intelligence supersedes that of individual scientists (Woolley et al. 2010), and the need for more interdisciplinary research collaborations has been voiced by the scientific community (Schwenk et al. 2009, Mykles et al. 2010). 


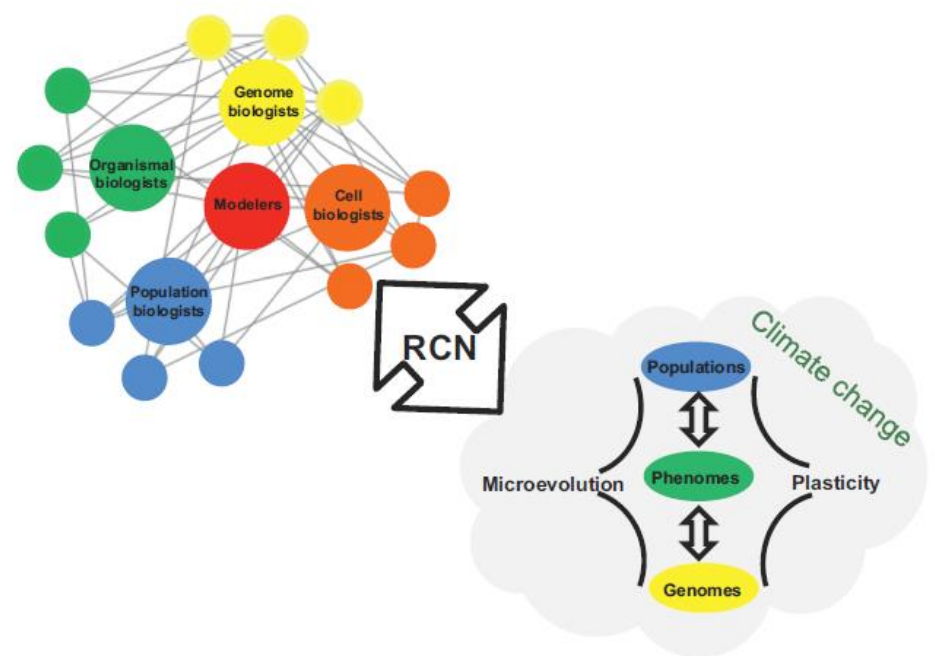

Figure 1. The g2p2pop Research Coordination Network consists of biologists specializing at the levels of the gene, the cell, the organism, and the population and modelers (A) who aim to tackle the challenge of predicting responses to climate change across levels of biological organization (B). Understanding and predicting climate change responses across levels of biological organization requires addressing the two pillars-microevolutionary processes and plasticity.

Here we present an effort that aims to coalesce groups that often do not interact, but their collaboration is essential to illuminate the complexities of life: empirical scientists and mathematical modelers, spanning levels of biological organization from genomes to organisms to populations. Insights into how systems function at different scales have the potential to provide a synthetic understanding of how animals operate and serve as the basis for quantitative models to predict resilience and vulnerability of species in a changing world. Thus, the overarching goal of our Research Coordination Network (RCN) titled "Predicting vertebrate responses to a changing climate: modeling genomes to phenomes to populations (g2p2pop)" is to facilitate, refine and diversify scientific discourse among biologists and mathematicians with expertise that spans from genomes to populations. We anticipate that the RCN will create pivotal linkages among multiple disciplines of biology and mathematics such that collaborations will form naturally and result in bidirectional interplay between theory and experimentation to develop unified mechanistic models of genomes to phenomes to populations (Figure 1). It is only through such interactions between Experts and interplay between theory, models, and data that we can hope to facilitate the generation of a new synthesis and a conceptual framework for biology across levels.

\section{Acknowledgements}

This paper is a product of discussions during workshops and meetings made possible by the NSF grant \#1656063 “Research Coordination Network (RCN): Predicting vertebrate responses to a changing climate: modeling genomes to phenomes to populations (G2P2PoP)" (https:// nau.edu/cbi-rcn-g2p2pop/). We thank the reviewers for their helpful comments.

\section{References}

Abrams, P.A., Harada, Y., Matsuda, H. 1993. On the relationship between quantitative genetic and ESS models. Evolution 47, 982-985.

Allen, T.F., Starr, T.B. 2017. Hierarchy: Perspectives for Ecological Complexity. University of Chicago Press.
Baldwin, R., Sainz, R. 1995. Energy partitioning and modeling in animal nutrition. Ann. Rev. Nutr. 15, 191-211.

Boutin, S., Lane, J.E. 2014. Climate change and mammals: evolutionary versus plastic responses. Evolut. Appl. 7, 29-41.

Caswell, H. 2001. Matrix Population Models: Construction, Analysis and Interpretation, $2^{\text {nd }}$ ed. Sinauer.

Del Giudice, M., Buck, C.L., Chaby, L.E., Gormally, B.M., Taff, C.C., Thawley, C.J., Vitousek, M.N., Wada, H. 2018. What is stress? A systems perspective. Integrative Comp. Biol. 58, 1.019-1.032.

DeLong, J.P., Forbes, V.E., Galic, N., Gibert, J.P., Laport, R.G., Phillips, J.S., Vavra, J.M. 2016. How fast is fast? Ecoevolutionary dynamics and rates of change in populations and phenotypes. Ecol. Evol. 6, 573-581.

DeLong, J.P., Gibert, J.P. 2016. Gillespie eco-evolutionary models (GEMs) reveal the role of heritable trait variation in eco-evolutionary dynamics. Ecol. Evol. 6, 935-945.

Diamond, S.E., Martin, R.A. 2016. The interplay between plasticity and evolution in response to human-induced environmental change. F1000 Res. 5.

Evans, M.R., Bithell, M., Cornell, S.J., Dall, S.R.X., Díaz, S., Emmott, S., Ernande, B., Grimm, V., Hodgson, D.J., Lewis, S.L., Mace, G.M., Morecroft, M., Moustakas, A., Murphy, E., Newbold, T., Norris, K.J., Petchey, O., Smith, M., Travis, J.M.J., Benton, T.G. 2013. Predictive systems ecology. Proc. R. Soc. B: Biol. Sci. 280.

Forbes, V.E., Railsback, S., Accolla, C., Birnir, B., Bruins, R.J.F., Ducrot, V., Galic, N., Garber, K., Harvey, B.C., Jager, H.I., Kanarek, A., Pastorok, R., Rebarber, R., Thorbek, P., Salice, C.J. 2019. Predicting impacts of chemicals from organisms to ecosystem service delivery: A case study of endocrine disruptor effects on trout. Sci. Total Environ. 649, 949-959.

Forbes, V.E., Salice, C.J., Birnir, B., Bruins, R.J.F., Calow, P., Ducrot, V., Galic, N., Garber, K., Harvey, B.C., Jager, H., Kanarek, A., Pastorok, R., Railsback, S.F., Rebarber, R., Thorbek, P. 2017. A framework for predicting impacts on ecosystem services from (sub)organismal responses to chemicals. Environ. Toxicol. Chem. 36, 845-859.

Galic, N., Forbes, V.E. 2017. The role of dynamic energy budget theory in predictive modeling of stressor impacts on ecological systems: Comment on: "Physics of metabolic organization" by Marko Jusup et al. Phys. Life Rev. 20, 43-45. 
Galic, N., Grimm, V., Forbes, V.E. 2017. Impaired ecosystem process despite little effects on populations: modeling combined effects of warming and toxicants. Glob. Change Biol. 23, 2,973-2,989.

Gibaldi, M., Perrier, D. 1982. Pharmacokinetics, $2^{\text {nd }}$ ed. Dekker.

Gillies, K., Krone, S., Nagler, J.J., Schultz, I.R. 2016. A computational model of the rainbow trout hypothalamus-pituitary-ovary-liver axis. PLoS Comput. Biol. 12.

Gotthard, K., Nylin, S. 1995. Adaptive plasticity and plasticity as an adaptation: a selective revie of plasticity in animal morphology and life history. Oikos 3-17.

Grimm, V., Railsback, S.F. 2005. Individual-Based Modeling and Ecology. Princeton University Press.

Hastings, A., Abbott, K.C., Cuddington, K., Francis, T., Gellner, G., Lai, Y.-C., Morozov, A., Petrovskii, S., Scranton, K., Zeeman, M.L. 2018. Transient phenomena in ecology. Science 361, eaat6412.

Houghton, J., Ding, Y., Griggs, D. Noguer, M., van der Linden, P. Dai, X., Maskell,K., Johnson, C. 2001. IPCC Climate Change: The Scientific Basis. Cambridge University Press.

Houston, A.I., McNamara, J.M. 1992. Phenotypic plasticity as a state-dependent life history decision. Evolut. Ecol. 6, 243-253.

Jusup, M., Sousa, T., Domingos, T., Labinac, V., Marn, N., Wang, Z., Klanjšček, T. 2017. Physics of metabolic organization. Phys. Life Rev. 20, 1-39.

Karr, J.R., Sanghvi, J.C., Macklin, D.N., Gutschow, M.V., Jacobs, J.M., Bolival Jr., B., Assad-Garcia, N., Glass, J.I., Covert, M.W. 2012. A whole-cell computational model predicts phenotype from genotype. Cell 150, 389-401.

Kearney, M., Porter, W. 2009. Mechanistic niche modelling: combining physiological and spatial data to predict species' ranges. Ecol. Lett. 12, 334-350.

Kooijman, S. 2010. Dynamic Energy Budget Theory for Metabolic Organisation. Cambridge University Press.

Lande, R. 1976. Natural selection and random genetic drift in phenotypic evolution. Evolution 30, 314-334.

Li, Z., Kroll, K., Jensen, K.M., Villeneuve, D.L., Ankley, G.T., Brian, J.V., Sepulveda, M.S., Orlando, E.F., Lazorchak, J.M., Kostich, M., Armstrong, B., Denslow, N.D., Watanabe, K.H. 2011. A computational model of the hypothalamic-pituitary-gonadal axis in female fathead minnows (Pimephales promelas) exposed to 17 a-ethynyl estradiol and $17 \beta$-trenbolone. BMC Syst. Biol. 5, 63.

Martin, B.T., Jager, T., Nisbet, R.M., Preuss, T.G., Grimm, V., 2013. Predicting population dynamics from the properties of individuals: across-level test of dynamic energy budget theory. Am. Nat. 181, 506-519.
Messer, P.W., Ellner, S.P., Hairston Jr., N.G. 2016. Can population genetics adapt to rapid evolution? Trends Genet. 32, 408-418.

Murphy, C.A., Rose, K.A., Thomas, P. 2005. Modeling vitellogenesis in female fish exposed to environmental stressors: predicting the effects of endocrine disturbance due to exposure to a PCB mixture and cadmium. Reprod. Toxicol. 19, 395-409.

Mykles, D.L., Ghalambor, C.K., Stillman, J.H., Tomanek, L. 2010. Grand challenges in comparative physiology: integration across disciplines and across levels of biological organization. Integrative Comp. Biol. 50, 6-16.

Nisbet, R., Muller, E., Lika, K., Kooijman, S. 2000. From molecules to ecosystems through dynamic energy budget models. J. Anim. Ecol. 69, 913-926.

Parmesan, C., Yohe, G. 2003. A globally coherent fingerprint of climate change impacts across natural systems. Nature 421, 37-42.

Rahmstorf, S., Coumou, D. 2011. Increase of extreme events in a warming world. Proc. Natl. Acad. Sci. USA 108, 17,90517,909 .

Romero, L.M., Platts, S.H., Schoech, S.J., Wada, H., Crespi, E., Martin, L.B., Buck, C.L. 2015. Understanding stress in the healthy animal-potential paths for progress. Stress 18, 491-497.

Schwenk, K., Padilla, D.K., Bakken, G.S., Full, R.J. 2009. Grand challenges in organismal biology. Integrative Comp. Biol. 49, 7-14.

Sluka, J.P., Fu, X., Swat, M., Belmonte, J.M., Cosmanescu, A., Clendenon, S.G., Wambaugh, J.F., Glazier, J.A. 2016. A liver-centric multiscale modeling framework for xenobiotics. PLoS One 11.

Williams, C.T., Buck, C.L., Sheriff, M.J., Richter, M.M., Krause, J.S., Barnes, B.M. 2017. Sex-Dependent Phenological Plasticity in an Arctic Hibernator. Am. Nat. 190, 854859.

Wingfield, J.C., Kelley, J.P., Angelier, F. 2011. What are extreme environmental conditions and how do organisms cope with them? Curr. Zool. 57, 363-374.

Woodward, G., Perkins, D.M., Brown, L.E. 2010. Climate change and freshwater ecosystems: impacts across multiple levels of organization. Philos. Trans. R. Soc. B: Biol. Sci. 365, 2,093-2,106.

Woolley, A.W., Chabris, C.F., Pentland, A., Hashmi, N., Malone, T.W. 2010. Evidence for a collective intelligence factor in the performance of human groups. Science 330, 686-688. 